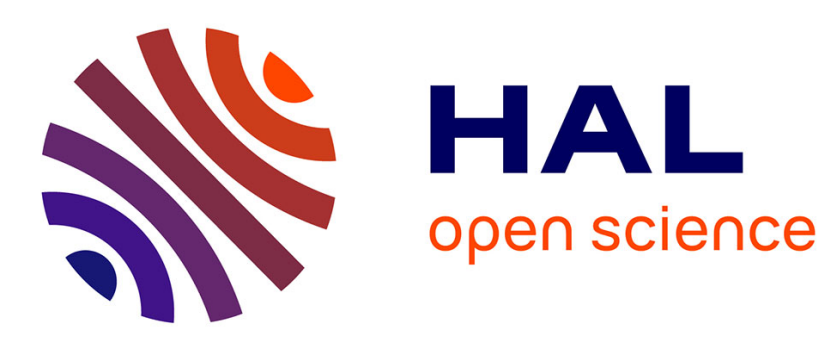

\title{
Investigation on the effect of impurities in xenon based dielectric barrier discharge lamps
}

a N Dagang, Sounil Bhosle, Georges Zissis, A Corazza

\section{To cite this version:}

a N Dagang, Sounil Bhosle, Georges Zissis, A Corazza. Investigation on the effect of impurities in xenon based dielectric barrier discharge lamps. Journal of Physics D: Applied Physics, 2010, 43 (23), pp.234006. 10.1088/0022-3727/43/23/234006 . hal-00569626

\section{HAL Id: hal-00569626 \\ https://hal.science/hal-00569626}

Submitted on 25 Feb 2011

HAL is a multi-disciplinary open access archive for the deposit and dissemination of scientific research documents, whether they are published or not. The documents may come from teaching and research institutions in France or abroad, or from public or private research centers.
L'archive ouverte pluridisciplinaire HAL, est destinée au dépôt et à la diffusion de documents scientifiques de niveau recherche, publiés ou non, émanant des établissements d'enseignement et de recherche français ou étrangers, des laboratoires publics ou privés. 


\title{
Investigation on the effect of impurities in xenon based dielectric barrier discharge lamps
}

\author{
A N Dagang ${ }^{1,2}, \mathrm{~S}$ Bhosle $^{1,3}, \mathrm{G}_{\text {Zissis }}{ }^{1,2}$ and A Corazza ${ }^{4}$ \\ ${ }^{1}$ Université de Toulouse, UPS, INPT, LAPLACE (Laboratoire Plasma et Conversion \\ d'Energie), 118 route de Narbonne, F-31062 Toulouse Cedex 9, France \\ ${ }^{2}$ CNRS LAPLACE, F-31062 Toulouse, France \\ ${ }^{3}$ LED Engineering Development, 11 rue du Mont Dore, F-31100 Toulouse, France \\ ${ }^{4}$ SAES Getters S.p.A, Viale Italia, 20020 Lainate, Milan, Italy \\ E-mail: ahmad.dagang@laplace.univ-tlse.fr
}

\begin{abstract}
In any discharges, the existence of impurities could give a severe change or bring a negative or positive effect to the discharge and plasma characteristics. The authors purposely added a few kinds of impurities and their effect on the discharge was investigated. The common and typical impurities of $\mathrm{H}_{2}, \mathrm{~N}_{2}, \mathrm{CO}_{2}$ and $\mathrm{CH}_{4}$ were applied in varying concentration percentages into a xenon DBD lamp. Their discharge condition, emission spectra and electrical characteristics were studied. The plasma generation differs from one type of impurity to another. With two different concentrations of hydrogen, at $5 \%$ concentration it would stabilize the discharge and at $0.5 \%$ concentrations it would give an additional collision process where a strong peak of atomic lines were observed. Nitrogen with two types of concentration i.e., $1 \%$ and $0.1 \%$ gives two kinds of characteristics in emission spectroscopy. From the electrical parameters, the voltage across the gap shows the lamps with impurities have a higher value compared to the pure xenon lamp.
\end{abstract}




\section{Introduction}

In dealing with vacuum sealing tubes the problems relating to impurities sometimes cannot be avoided. The main impurities are typically from hydrogen $\left(\mathrm{H}_{2}\right)$, nitrogen $\left(\mathrm{N}_{2}\right)$, carbon monoxide $(\mathrm{CO})$, carbon dioxide $\left(\mathrm{CO}_{2}\right)$, methane $\left(\mathrm{CH}_{4}\right)$, etc. The impurities can come out from the pumping system or from water vapor. It has been recognized that a small amount of water vapor will catalyze the dissociation of $\mathrm{O}_{2}$ in electrical discharges, and $\mathrm{N}_{2}, \mathrm{NO}, \mathrm{N}_{2} \mathrm{O}$ and $\mathrm{H}_{2}$ were also found to have this catalytic effect $[1,2]$. They also can be out gassed from the discharge tube itself when quartz or fused silica tubes are used, and where they may contain relatively high quantities of hydroxyl radical $\left(\mathrm{OH}^{-}\right)$that can be dissociated into $\mathrm{O}$ and $\mathrm{H}[3]$. Particularly in lamps, the presence of hydrogen even in a few parts per million (PPM) in the tube can cause an increase in starting voltage and ignition problems especially in high intensity discharge (HID) lamps[4].

Xenon based discharge has been identified as an alternative candidate to mercury, and as such the authors have used xenon based discharge in an effort to develop mercuryfree lamps. Xenon is non-toxic gas and is chemically stable compared to mercury. In low pressure discharge xenon emits strong resonance and excimer emissions in vacuum ultra violet (VUV) regions that can be converted with good efficiency in UV to visible light through phosphor. Xenon low pressure lamps such as exciplex lamp (xenon with halogens) was developed to be used for sterilization and medical treatment[5]. In high pressure discharge it is able to emit strong continuum emissions in visible regions[6], where xenon high pressure arc discharge lamp has been used such as in spectrophotometer. Xenon arc lamp also has a good color rendering with extremely high luminance, for example Osram XBO lamp which has been used for cinema film projection, light guide system, etc. Xenon based discharge also has an advantage in temperature-independence, capable of instant starting and restarting compared to mercury lamps as there is no evaporation process required. Many efforts have been undertaken by a number of researchers using $\mathrm{DC}, \mathrm{AC}$ or pulse, with conventional type discharge (with electrode), with electrodeless type discharge such as dielectric barrier discharge (DBD), inductively coupled plasma (ICP) and microwave discharge, and their performance has been improving[7-13].

In order to avoid any contamination from the internal electrodes, an electrodeless discharge DBD was applied. DBD is one type of capacitive coupled plasma which has been used mainly in developing excimer lamps and is also one of the most common types of industrial plasma sources. It is the simplest type of electrodeless discharge, essentially consisting of two electrodes separated by a small distance of dielectric material. The authors applied DBD to a small-gap discharge tube to make it easy to obtain a single filament discharge. This is important in order to obtain an intense filament-like discharge due to the difficulties in getting better emission spectra from the low intensity of glowlike discharge.

As an initial step towards the aim of developing mercury-free light sources, xenon low pressure with the purposely inserted impurities lamps are used. In this paper, the 
studies are focused on the effect of impurities on xenon DBD lamp, and the possibility of the mix gases (impurities with xenon) to be applied as a light source. The effects of typical type of impurities i.e. $\mathrm{H}_{2}, \mathrm{~N}_{2}, \mathrm{CO}_{2}$ and $\mathrm{CH}_{4}$ are evaluated, and applied using pulsed AC high voltage. Their discharge condition, spectroscopic and electrical characteristics are investigated.

\section{Experimental setup}

\subsection{Lamps and plasma generation}

The schematic diagram and experimental setup are shown in figures 1 and 2. The lamps (discharge tubes) used are a cube type quartz tube $(12 \times 12 \mathrm{~mm})$ with a glass thickness of $1 \mathrm{~mm}$ as described in figure 1 . The lamp was ignited using a DBD source. The DBD is supplied with pulse voltage with the amplitude ranging from 5 to $6 \mathrm{kV}$, at a pulse width of $1 \mu \mathrm{s}$, and the frequency is changed from 70 to $150 \mathrm{kHz}$. In some cases, in order to ignite the plasma an auxiliary excitation is needed. In this case a pen type Hg-Ar lamp is used as an ignitor by lighting it near to the lamp then removing when the plasma is produced. The compositions of each lamp are shown in table 1.

\subsection{Spectroscopic measurement}

Emission spectra were measured using Ocean Optics HR4000, a high resolution miniature fibre optic spectrometer. This spectrometer can provide an optical resolution at $0.025 \mathrm{~nm}$ and is responsive from 200 to $1100 \mathrm{~nm}$. Fibre used is $400 \mu \mathrm{m}$ in diameter, a UV-VIS High OC content type with its most efficient wavelength at 300 to $800 \mathrm{~nm}$. The setup is shown in figure 1 composed with fiber, spectrometer and personal computer. Since the plasma intensity is different from one lamp to another, the integration time of the spectrometer was changed accordingly from 200 to $2000 \mathrm{~ms}$ (longer time for less intense plasma). The spectroscopic sensitivity was calibrated using a Mikropack GmbH DT-Mini-2-GS deuterium halogen standard light source.

\subsection{Electrical parameters measurement}

For every discharge, the applied voltage and current were measured. They were measured using a Pintek Electronics high voltage probe HVP20AC/30DC (5 MHz) and a Tektronix P6021 $10 \mathrm{~mA} / \mathrm{mV}(120 \mathrm{kHz} \sim 60 \mathrm{MHz})$ current probe for voltage and current measurements respectively. A Tektronix P2220 1x/10x (200 MHz) voltage probe was used to measure the displaced charge across the lamp. The waveforms were recorded using a digital oscilloscope Tektronix TDS $2024(200 \mathrm{MHz})$.

\section{Technique to determine the electrical parameters in $D B D$}

Based on measured $V-I$ (voltage and current) and $V-Q$ (Lissajous diagram) results, the internal electric parameters such as voltage across the dielectric, voltage across the gap, 
discharge current, excitation power and energy inputted into plasma can be calculated. The equivalent circuit and DBD electrode configuration is shown in figure 2. The main equations are shown below[5].

$$
\begin{aligned}
& \text { Gas gap voltage : } U_{\mathrm{g}}(t)=U(t)-U_{\text {die }}(\mathrm{t}) \\
& \text { Dielectric voltage : } U_{\text {die }}(t)=\frac{Q(t)}{C_{\text {die }}} \\
& \text { Total charge : } Q(t)=U_{\text {add }}(t) C_{\text {add }} \\
& \text { Gas capacitance : } C_{\mathrm{g}}=\frac{C_{\text {lamp }} C_{\text {die }}}{C_{\text {die }}-C_{\text {lamp }}} \\
& \text { Discharge current : } I_{\mathrm{d}}(t)=I(t)-C_{\mathrm{g}} \frac{\partial U_{\mathrm{g}}}{\partial t} \\
& \text { Excitation power : } P(t)=U_{\mathrm{g}}(t) I_{\mathrm{d}}(t) \\
& \text { Inputted energy : } E(t)=\int_{0}^{t} P\left(t^{\prime}\right) d t^{\prime}
\end{aligned}
$$

Measured voltage and current are described as $U(t)$ and $I(t)$ respectively. $Q(t)$ can be calculated by measuring voltage drop $U_{\text {add }}$ across an additional capacitor $C_{\text {add }}$ that connected in series to the lamp as shown in figure 2. The value of $C_{\text {add }}$ is determined based on the basis of $Z_{\text {add }} \ll Z_{\text {lamp }}$, here the authors used $C_{\text {add }}=100 \mathrm{pF}$. Dielectric capacitance $C_{\text {die }}$ is simplified to one capacitance and its value together with lamp capacitance $C_{\text {lamp }}$ value can be obtained from the slope of the corresponding segments of $V-Q$ characteristics[13].

\section{Results}

\subsection{Plasma condition}

Discharge images for each lamp are shown in figure 3 for frequencies 80, 100, 120 and $140 \mathrm{kHz}$. For each discharge there are differences in plasma intensity and stability. As can be seen in figure 3, lamps 1 and 5 produced a thick filament-like discharge compared to the rest of the lamps. This shows these two lamps have relatively high intensity and are more stable. For lamps 3, 4 and 6, the discharge was getting unstable (filament kept moving) when the frequency is increased. The most stable plasma produced was from lamp 2, where the position of a filament remained unchanged when the frequency was adjusted. Instead, its filament becomes diffuse when frequency is increased. Lamp 2 is a lamp with a high concentration of $\mathrm{H}_{2}$, and this condition can be considered one of the reasons for obtaining stable plasma compared with lamp 3 with low concentration of $\mathrm{H}_{2}$ which was unstable. Lamp 7 with high concentration of $\mathrm{CH}_{4}$ is the most difficult to ignite the plasma, the intensity is the lowest among the lamps but the discharge was stable. 


\subsection{Emission spectra}

Emission spectra for the lamp with pure xenon and the lamps with each impurity $\left(\mathrm{H}_{2}\right.$, $\mathrm{N}_{2}, \mathrm{CO}_{2}, \mathrm{CH}_{4}$ ) at the frequencies of $80,100,120 \mathrm{kHz}$ are shown in figures 4,5 and 6 respectively. A discussion here will focus on near UV and visible regions as shown in the figures with wavelength of $300 \sim 800 \mathrm{~nm}$, the most efficient range of spectrometer and fiber. As can be seen in figures $4 \sim 6$, when the frequency is increased emission spectra intensities decreases, while emitted spectra and waveforms remain unchanged. For these four types of impurities, the molecular spectra only can be observed in the lamp with nitrogen at $1 \%$ concentration (lamp 4) where typical 2nd positive band of $\mathrm{N}_{2}$ molecular spectra can be seen at $300 \sim 400 \mathrm{~nm}$. However for the lamp with nitrogen at $0.1 \%$ concentration (lamp 5), there are no particular atomic or molecular lines that can be observed except xenon atomic $764.20 \mathrm{~nm}$ and in this case the waveform is similar to lamp 1 , where a weak continuum emission can be seen at $350 \sim 450 \mathrm{~nm}$ and $500 \sim 550 \mathrm{~nm}$. For the other lamps, most of the lines that can be seen are from xenon atomic spectra. The lines are mainly assigned to xenon atomic lines of 450.10, 467.12, 473.41, 491.65 nm that belong to transitions originating from $5 \mathrm{p}^{5} 6 \mathrm{p}\left(2 \mathrm{p}_{1}\right.$ to $\left.2 \mathrm{p}_{10}\right)$ configuration at energy levels between $9.58 \mathrm{eV}$ and $11.98 \mathrm{eV}$. In the case of $0.5 \%$ hydrogen contained lamp (lamp 3), the typical hydrogen atomic lines of $656.28 \mathrm{~nm}, 486.13 \mathrm{~nm}$ and $434.05 \mathrm{~nm}$ (for hydrogen $\alpha, \beta, \gamma)$ cannot be observed. Xenon atomic lines of $467.12 \mathrm{~nm}, 688.21 \mathrm{~nm}, 711.96 \mathrm{~nm}$ and $764.20 \mathrm{~nm}$ are strongly observed. The same observation goes to the $5 \%$ hydrogen contained lamp (lamp 5) but the atomic lines are weaker. In case of lamps with $\mathrm{CO}_{2}$ and $\mathrm{CH}_{4}$ (lamps 6 and 7), these have relatively low intensity and it is difficult to identify the spectra lines due to the noise that was simultaneously observed. However, as in previous cases, xenon atomic lines of $476.12 \mathrm{~nm}$ and $764.20 \mathrm{~nm}$ can be clearly identified.

\subsection{Electrical characteristics}

Figure 7 shows an example of the measured waveforms of applied voltage, total current and a Lissajous diagram $(V-Q)$ of displaced charge. Dielectric capacitance $C_{\text {die }}$ and lamp capacitance $C_{\text {lamp }}$ were defined using corresponding slopes of a Lissajous diagram. Based on these results, gas gap voltage $V_{\mathrm{g}}$, discharge current $I_{\mathrm{d}}$, excitation power $P$ and inputted energy $E$ were calculated and shown in figure 8 for lamp 1 as an example. Detailed values of each peak for every lamp at 80, 100 and $120 \mathrm{kHz}$ are shown in table 2. As can be seen from the table, when the frequency is increased the values of gas gap voltage, discharge current and excitation power decreases, while the inputted energy shows uncertain tendency. The gas gap voltage of lamps with impurities is higher (except lamp 2 at higher frequency) than pure xenon lamp (lamp 1). At all frequencies, the gas gap voltage for lamps with higher hydrogen concentration lamp and pure xenon lamp (lamps 1 and 2) are the lowest and is approximately 0.5 to $1.5 \mathrm{kV}$ lower than other lamps. In the case of discharge current and excitation power, the nitrogen concentration lamps (lamps 4 and 5) are the lowest and the lamp with lower hydrogen concentration (lamp 3) is highest among the lamps. The excitation power for lamps with hydrogen and 
carbon elements (lamps 3,6,7) are much higher than rest of the lamps. The inputted energy for the xenon lamp (lamp 1), is higher compared to the lamps with impurities (except lamp 4) at $100 \mathrm{kHz}$ but lower at $120 \mathrm{kHz}$.

\section{Discussion}

\subsection{Effect of hydrogen $\left(H_{2}\right)$}

Hydrogen has been used because of it is the most common impurity in the vacuum tube. Two different concentrations of $\mathrm{H}_{2}(0.5 \%$ and $5 \%)$ have been used. From these two conditions, a big difference in terms of discharge stability is observed. With a high concentration of $\mathrm{H}_{2}$ (5\% of $\mathrm{H}_{2}$, lamp 2), plasma that is produced being more stable meaning there is no unconditional movement compared to the low concentration $(0.5 \%$ of $\mathrm{H}_{2}$, lamp 3) where plasma moves timely even without any change in the supplied power. As can be seen from the discharge images in figure 3, discharge at lamp 2 is more diffused which is something that favors the use of phosphor, whereas discharge at lamp 3 is more constricted. Electrical parameters as in table 2 for these two lamps show that the discharge current for lamp 2 is much lower compared to the lamp 3 at all frequencies. In xenon discharge, one of the characteristics is that its tends to constrict at high current density, and the result shows this tendency. In other words, it shows that $\mathrm{H}_{2}$ can work as a discharge stabilizer which can avoid an unstable filamentary state at high percentages of concentration. In development of xenon fluorescent lamp, in order to obtain large luminous flux, a diffuse glow discharge with higher xenon pressure or large input current or power is required[8]. Because of the characteristics of xenon discharge as mentioned above it is difficult to realize. From the authors results, there is a possibility of diffuse xenon-hydrogen discharge at higher current density that could be obtained by adding some small percentage of hydrogen (percentage need to be optimized).

In terms of emission spectra, as can be seen in figures 4 and 5 only from $\mathrm{H}_{2}$ concentration lamps a strong peak of xenon atomic lines can be observed. For example the red xenon atomic lines of $618.24 \mathrm{~nm}$ and $631.81 \mathrm{~nm}$ at energy level between $9.68 \mathrm{eV}$ and $11.68 \mathrm{eV}$ which cannot be observed in other lamps included the xenon reference lamp. Furthermore, a weak continuum emission also can be seen at 450 700 nm. From these results of strong atomic lines and continuum emission, the presence of $\mathrm{H}_{2}$ in a small amount causes additional collision processes, could change the electron power balance which bring larger power losses in collision and consequently resulted more excitation, ionization and electron-ion recombination processes. The more excitation, ionization and recombination processes occur, the more excitation power will be needed. This is supported by the results from the electrical parameters where for the lamps containing a hydrogen element, where their excitation power is higher compared to other lamps. The increase of excitation process (strong atomic lines and continuum emission) especially in lamp 3 also could be due to autoionising states of xenon produced in negative hydrogen ions $\left(\mathrm{H}^{-}\right)[14,15]$. Curran et al.[15] reported that the mixture of hydrogen-xenon gases 
causes a very large increase in the electron density.

\subsection{Effect of nitrogen $\left(N_{2}\right)$}

Nitrogen was used in order to see the effect of its 2nd positive band lying around $350 \mathrm{~nm}$, and also to obtain an excitation by low energy electrons. Xenon discharge does not have an inelastic collision cross section below $8.3 \mathrm{eV}$. However, nitrogen has an excitation probability at $1.4 \sim 4 \mathrm{eV}$, the process which is due to the vibrational heating[16]. $\mathrm{N}_{2}$ in low concentration $(0.1 \%$, lamp 5$)$ produced a more intense and stable plasma compared to the higher one $\left(1 \%\right.$, lamp 4). This condition is vice-versa with the $\mathrm{H}_{2}$ concentration lamp in terms of discharge stability. However it is less stable than the $\mathrm{H}_{2}$ concentration lamp where in the case of $\mathrm{N}_{2}$ when the frequency is increased it tends to move. However at a low $\mathrm{N}_{2}$ concentration, with a thick filament the intensity is high but this tendency is not of a much benefit in developing xenon fluorescent lamps. This is because a strong filamentary discharge could minimize phosphor excitation. There are no strong atomic lines that can be observed from the emission spectra. The waveform is similar with a xenon lamp but the continuum emissions at 350 450 nm and 500 550 nm that can be seen strongly in the xenon lamp are significantly weaker. In the case of higher concentrations, molecular spectra can be observed at near UV with the continuum emissions at $620 \sim 700 \mathrm{~nm}$ and $720 \sim 780 \mathrm{~nm}$. The near UV lines would be appropriate for phosphor excitation with less Stokes loses. The continuum emissions at wavelengths in the red color region may not be so helpful in obtaining a white color light source, but they could be used to give a balance in color rendering if the blue and green spectrum can be produced using phosphor excitation.

In terms of electrical parameters, its discharge current and excitation power are the lowest among the lamps. This could be due to the low excitation energy of nitrogen molecule. As mentioned above, vibrational-excited nitrogen molecules need only around $4 \mathrm{eV}$ to be excited and this low energy electron could help to produce the excited nitrogen molecules and consequently generate excited xenon atoms[16].

\subsection{Effect of carbon $\left(\mathrm{CO}_{2}\right.$ and $\left.\mathrm{CH}_{4}\right)$}

The lamps with carbon elements $\left(\mathrm{CO}_{2}\right.$ and $\mathrm{CH}_{4}$ concentration lamps) were the most difficult among the used lamps in terms of plasma ignition which is needed to give a longer time of auxiliary excitation. The discharge of the $\mathrm{CO}_{2}$ concentration lamp is not stable with all values of frequency. For the $\mathrm{CH}_{4}$ concentration lamp, the discharge is stable but its intensity is significantly low, the lowest among the lamps. The unstable filamentary discharge and an extremely low intensity make it the integration time of spectrometer needed to be increased. As a result, emission spectra obtained from the lamps were accumulated with noises. The initial target of this kind of concentration (with the carbon element) was to obtain the $\mathrm{C}_{2}$ swan bands molecular spectra which is believed to produce a white light and an intense plasma. This is because the swan system bands $\mathrm{A}^{3} \prod_{\mathrm{g}}-\mathrm{X}^{\prime 3} \prod_{\mathrm{u}}[17]$, have a broad molecular spectra in visible regions lying 
on wavelength of $430 \sim 660 \mathrm{~nm}$ with several main heads. Kado et al. [18] reported the possibility of producing $\mathrm{C}_{2}$ molecules from methane $\mathrm{DBD}$, however, with the authors current setup, it could be there is not enough energy to dissociate the molecules. It was not only $\mathrm{C}_{2}$, the other spectra from molecular dissociation such as $\mathrm{H}_{2}, \mathrm{O}_{2}, \mathrm{CO}$ and $\mathrm{OH}$ radical also cannot be identified. From the electrical parameter results, the gas gap voltage and the power excitation of these lamps can be considered high enough (compared to the results of the excimer lamp in reference 5) to dissociate the molecules and it could be that the method of spectroscopy measurement needs to be changed. The next approach that could be considered is to increase the applied voltage and at the same time improve the method of spectroscopy measurement.

\section{Conclusion}

The basic investigations on the effects of typical impurities have been done. The use of $\mathrm{H}_{2}$ at $5 \%$ of concentration could help to diffuse and stabilize the plasma and at another concentration of $0.5 \%$ it could increase the excitation, ionization and recombination processes. $\mathrm{N}_{2}$ with a low concentration lamp does not fulfil the target to see a strong emission at near UV but with a high concentration lamp a significant emission spectra can be observed. With two different characteristics obtained from emission spectra, the other results with different concentration are preferable. In the case of $\mathrm{CO}_{2}$ and $\mathrm{CH}_{4}$ concentration lamps, typical molecular spectra cannot be observed. Together with the $\mathrm{H}_{2}$ concentration lamps, a high excitation power is obtained from their discharge. As such it is believed that by changing the method or setup of spectroscopy measurement, a molecular spectrum could be observed. This will be the next step of the research and the work is ongoing.

\section{Acknowledgments}

The authors would like thank Quantel Group for their support in providing the power supply. This work was done in collaboration between SAES Getters (Milan, Italy) and ADPA-LAPLACE (Toulouse, France). The research activities were partly funded by SAES Getters.

\section{References}

[1] Brown R L 1967 J. Phys. Chem. 71 2492-95

[2] Copeland L C 1930 Phys. Rev. 36 1221-31

[3] Maagt B J and Corazza A 2005 J. Phys. D: Appl. Phys. 38 3066-70

[4] Boffito C and Corazza A 2004 Proc. 10th Int. Symp. on Science and Technology of Light Sources (Toulouse, France) 95-104

[5] Lomaev M I, Sosnin E A, Tarasenko V F, Shits D V, Skakun V S, Erofeev M V and Lisenko A 2006 Instruments and Exp. Tech. 49 595-616

[6] Henderson S T and Marsden A M 1972 Lamps and Lighting (Edward Arnold Publishers) 
[7] Uhrlandt D, Bussiahn R, Gorchakov S, Lange H, Loffhagen D and Nötzold D 2005 J. Phys. D: Appl. Phys. 38 3318-25

[8] Jinno M, Okamoto M, Takeda M and Motomura H 2007 J. Phys. D: Appl. Phys. 40 3889-95

[9] Beleznai S, Mihajlik G, Agod A, Maros I, Juhasz R, Németh Z, Jakab L and Richter P $2006 \mathrm{~J}$. Phys. D: Appl. Phys. 39 3777-87

[10] Dagang A N, Kondo A, Motomura H and Jinno M 2009 J. Phys. D: Appl. Phys. 42 1-8

[11] Ametepe J D, Diggs J, Manos D M and Kelly M J 1999 J. Appl. Phys. 85 7505-10

[12] Nazri A, Kondo A, Takeda T, Motomura H and Jinno M 2007 Proc. 11th Int. Symp. on Science and Technology of Light Sources (Shanghai, China) 605-06

[13] Zoran F and Coogan J J 1996 J. Phys. D: Appl. Phys. 30 817-25

[14] Penent F, Grouard J P, Montmagnon J L and Hall R I 1990 J. Phys. B: At. Mol. Pot. Phys 23 L449-54

[15] Curran N P, Hopkins M B, Vender D and James B W 2000 Plasma Sources Sci. Technol. 9 169-75

[16] Park K W, Hwang H S, Han M H, Baik H K and Song K M 2008 Appl. Phys. Lett. 92061502

[17] Pearse R W B and Gaydon A G 1976 The Identification of Molecular Spectra (Cambridge: Chapman and Hall)

[18] Kado S, Sekine Y, Nozaki T and Okazaki K 2004 Catalysis Today 89 47-55 


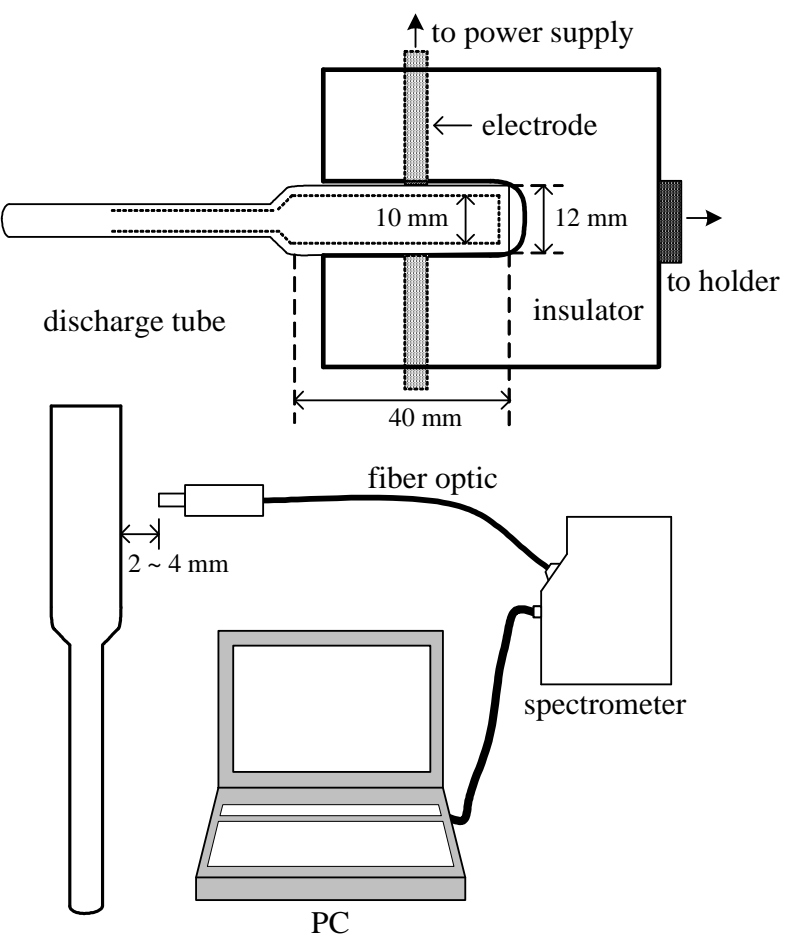

Figure 1. Experimental setup with a tube dimension diagram.

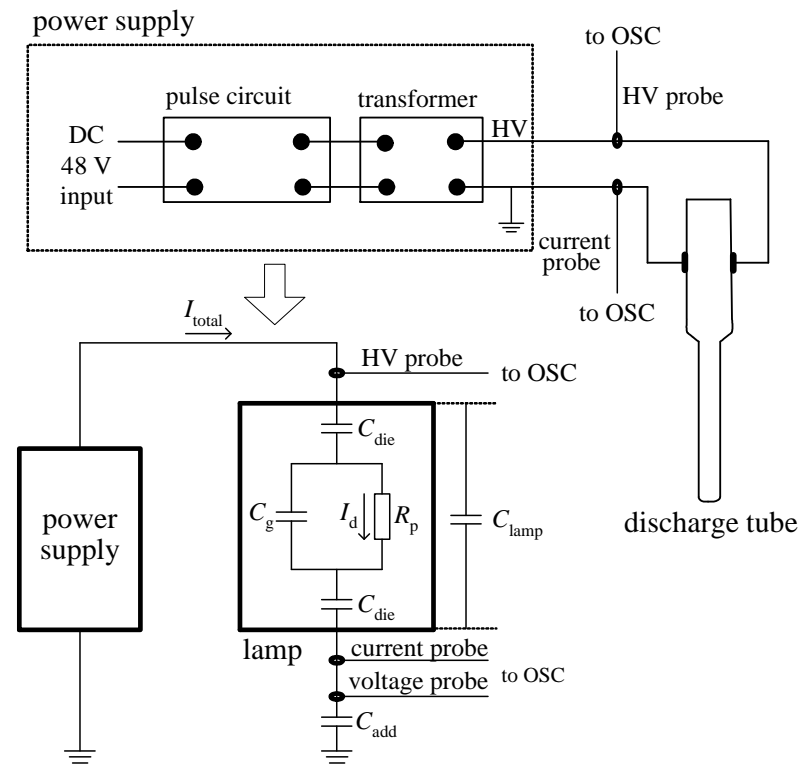

Figure 2. A schematic diagram of the power supply and an equivalent circuit of DBD. Gas capacitance $C_{\mathrm{g}}$, dielectric capacitance $C_{\mathrm{die}}$, additional capacitance $C_{\text {add }}$, discharge current $I_{\mathrm{d}}$ and plasma resistance $R_{\mathrm{p}}$. 
Table 1. Lamps number and their corresponding compositions. All lamps are with a total pressure of 150 Torr.

\begin{tabular}{|c|c|}
\hline Lamp No. & Gas composition \\
\hline 1 & $\mathrm{Xe}$ \\
\hline 2 & $\mathrm{Xe}-\mathrm{H}_{2}(95 \%-5 \%)$ \\
\hline 3 & $\mathrm{Xe}-\mathrm{H}_{2}(99.5 \%-0.5 \%)$ \\
\hline 4 & $\mathrm{Xe}-\mathrm{N}_{2}(99 \%-1 \%)$ \\
\hline 5 & $\mathrm{Xe}-\mathrm{N}_{2}(99.9 \%-0.1 \%)$ \\
\hline 6 & $\mathrm{Xe}-\mathrm{CO}_{2}(99.5 \%-0.5 \%)$ \\
\hline 7 & $\mathrm{Xe}-\mathrm{CH}_{4}(95 \%-5 \%)$ \\
\hline
\end{tabular}

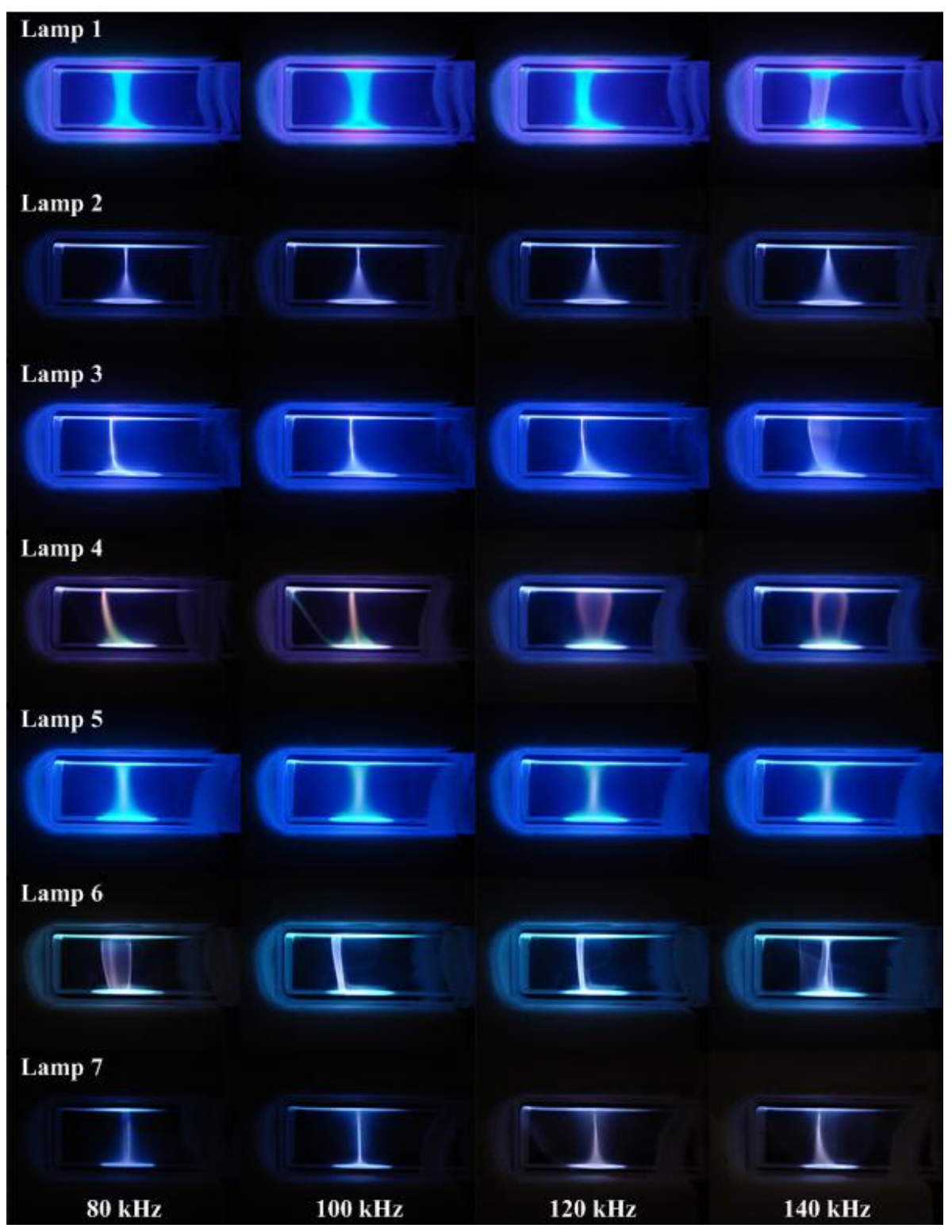

Figure 3. Discharge images for lamps $1 \sim 7$ at frequency of 80, 100, 120 and $140 \mathrm{kHz}$. 


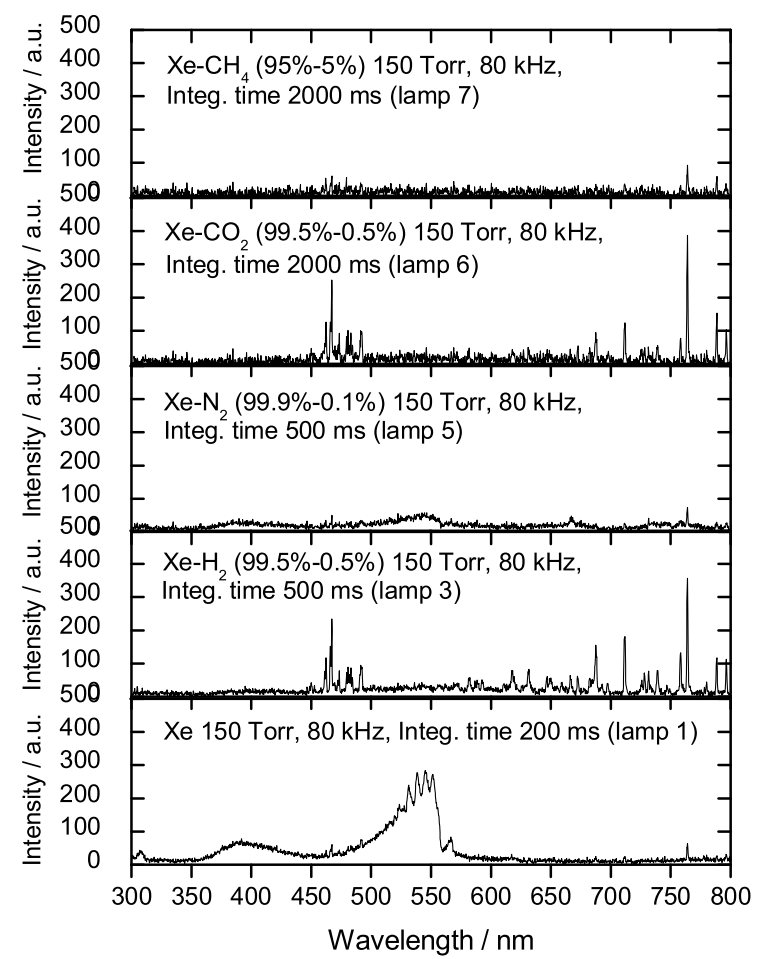

Figure 4. Emission spectra of the lamps with xenon reference lamp and impurities concentration lamps (lamps 3,5,6,7) at frequency $80 \mathrm{kHz}$.

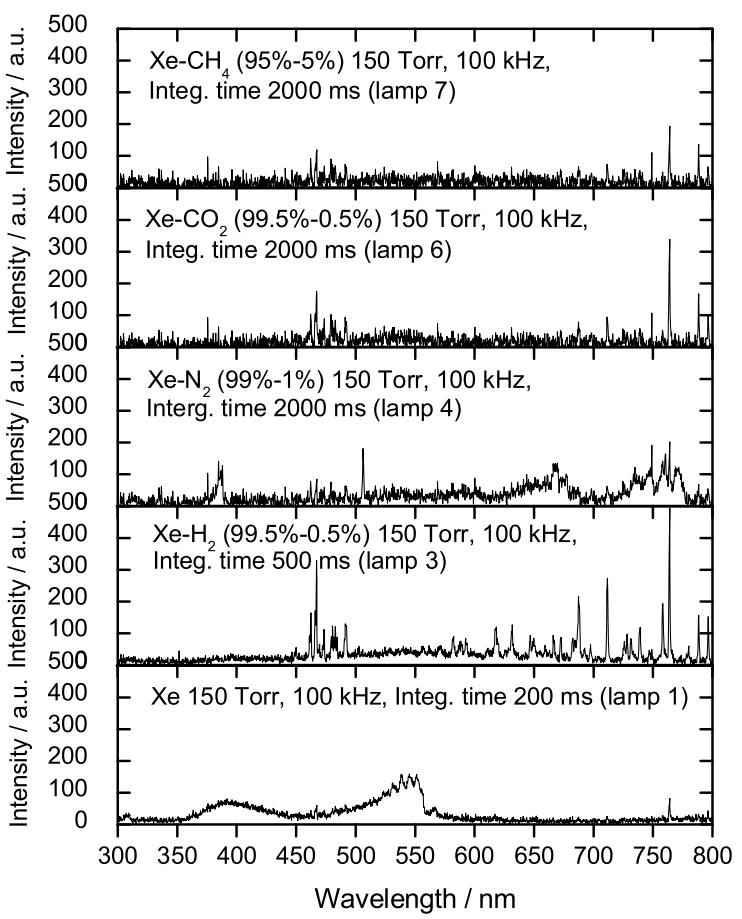

Figure 5. Emission spectra of the lamps with xenon reference lamp and impurities concentration lamps (lamps 3,4,6,7) at frequency $100 \mathrm{kHz}$. 


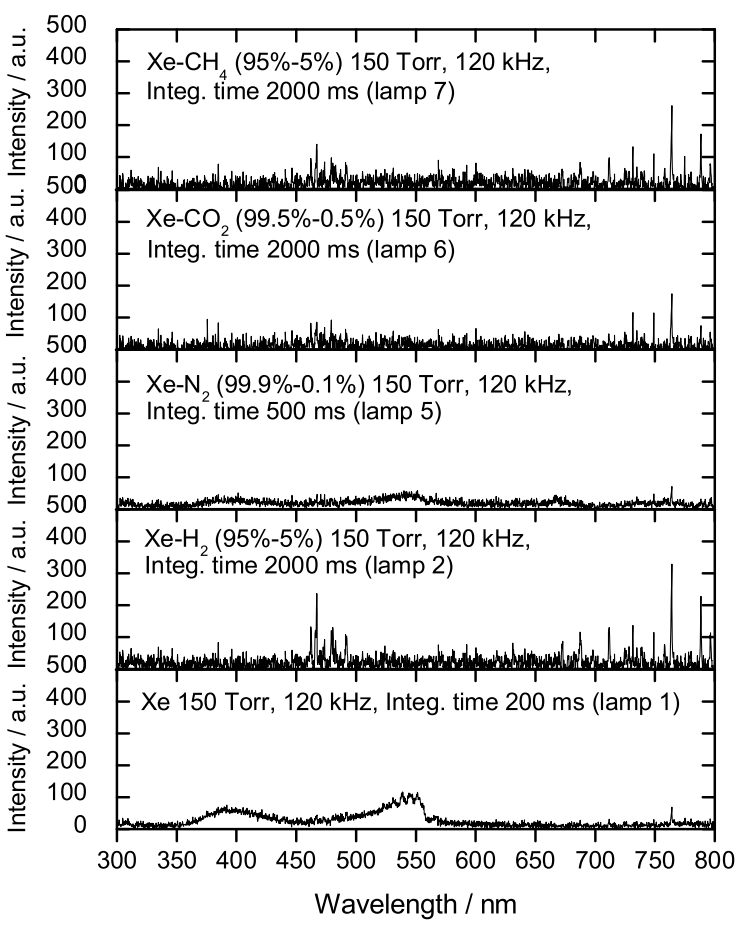

Figure 6. Emission spectra of the lamps with xenon reference lamp and impurities concentration lamps (lamps 2,5,6,7) at frequency $120 \mathrm{kHz}$.
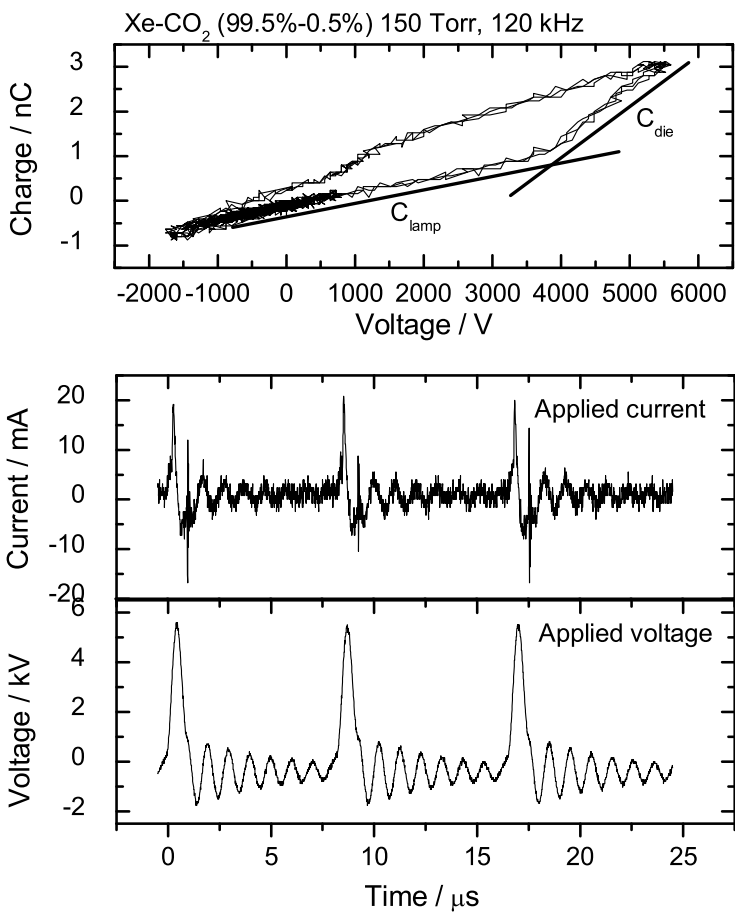

Figure 7. An example of the measured results of applied voltage, total current and displaced charge (Lissajous diagram). 


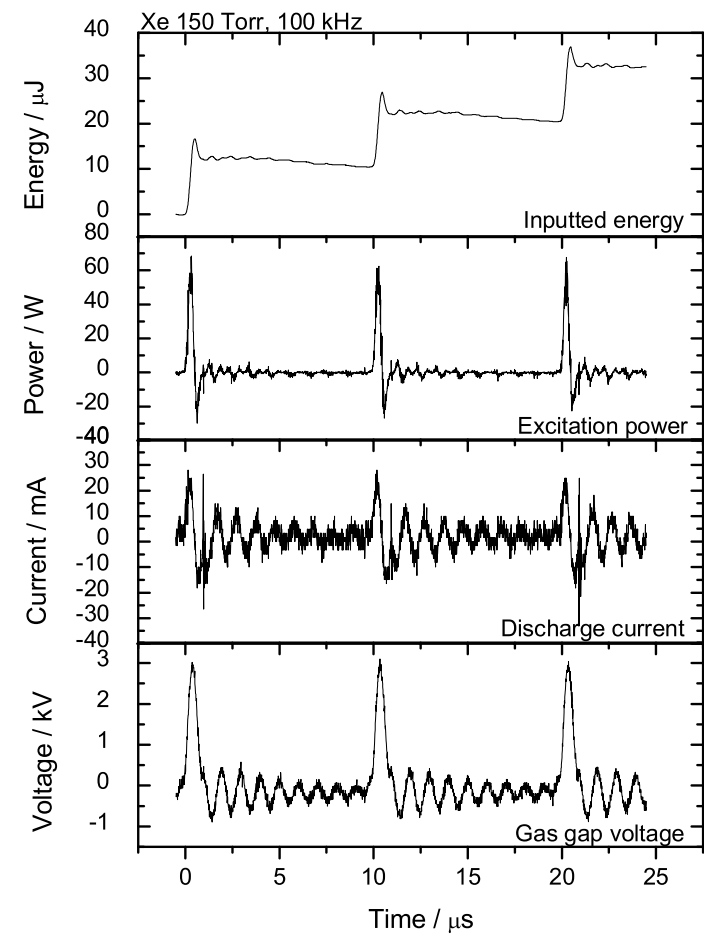

Figure 8. Electrical parameters of lamp 1 (Xe 150 Torr), xenon reference lamp. 
Table 2. Peak values of voltage across the gap, discharge current, excitation power and inputted energy at frequency of 80,100 and $120 \mathrm{kHz}$, for $25 \mu$ s period.

\begin{tabular}{|c|c|c|c|c|}
\hline $\begin{array}{c}\text { Frequency / } \\
\text { Lamp No. }\end{array}$ & $\begin{array}{c}\text { Voltage }(\mathrm{kV}) \\
\text { (peaks average) }\end{array}$ & $\begin{array}{c}\text { Current (mA) } \\
\text { (peaks average) }\end{array}$ & $\begin{array}{c}\text { Power }(\mathrm{W}) \\
\text { (peaks average) }\end{array}$ & $\begin{array}{l}\text { Energy }(\mu \mathrm{J}) \\
(1 \text { st period })\end{array}$ \\
\hline \multicolumn{5}{|l|}{$80 \mathrm{kHz}$} \\
\hline 1 & 2.91 & 20.89 & 52.12 & 22.40 \\
\hline 2 & 3.17 & 26.73 & 84.28 & 23.10 \\
\hline 3 & 3.99 & 38.05 & 135.37 & 23.90 \\
\hline 4 & 3.82 & 17.13 & 51.80 & 21.20 \\
\hline 5 & 3.46 & 19.95 & 54.18 & 21.50 \\
\hline 6 & 3.81 & 35.19 & 119.47 & 22.30 \\
\hline 7 & 4.46 & 27.01 & 119.38 & 23.90 \\
\hline \multicolumn{5}{|l|}{$100 \mathrm{kHz}$} \\
\hline 1 & 3.02 & 25.90 & 66.05 & 26.90 \\
\hline 2 & 2.50 & 24.43 & 61.94 & 22.30 \\
\hline 3 & 3.66 & 34.76 & 111.11 & 23.30 \\
\hline 4 & 4.11 & 19.29 & 65.88 & 27.60 \\
\hline 5 & 3.76 & 20.51 & 54.50 & 19.50 \\
\hline 6 & 3.12 & 34.84 & 89.86 & 20.90 \\
\hline 7 & 4.03 & 22.89 & 90.77 & 24.80 \\
\hline \multicolumn{5}{|l|}{$120 \mathrm{kHz}$} \\
\hline 1 & 2.91 & 21.14 & 51.35 & 20.80 \\
\hline 2 & 2.08 & 23.75 & 47.11 & 21.70 \\
\hline 3 & 3.29 & 32.54 & 99.23 & 21.50 \\
\hline 4 & 3.50 & 18.42 & 49.11 & 20.8 \\
\hline 5 & 3.28 & 22.38 & 55.08 & 21.60 \\
\hline 6 & 3.06 & 27.43 & 80.40 & 23.00 \\
\hline 7 & 3.24 & 21.15 & 64.10 & 21.70 \\
\hline
\end{tabular}

